\title{
THE IMPACT OF KNOWLEDGE SHARING CAPABILITY ON INNOVATION CAPABILITY WITH THE MEDIATING ROLE OF ISLAMIC WORK ETHIC AMONG EMPLOYEES OF ELECTRICITY DISTRIBUTION COMPANY OF GUILAN PROVINCE
}

\author{
Seyavash Ghasemalipour Selakjani \\ Department of Public Administration, Rasht Branch, Islamic Azad University, Rasht, Iran \\ seyavashghalipour@gmail.com \\ Hamidreza Rezaei Kelidbari \\ Department of Public Administration, Faculty of Management and Accounting, Rasht Branch, Islamic \\ Azad University, Rasht, Iran \\ Hrezaee41@yahoo.com
}

\begin{abstract}
Knowledge sharing capability is an important strategy that the organization implements in order to create value and increase survival in today's complex and variable environment. Innovation capability is the most important defining characteristic of performance. Innovation can be provided through a focus on innovation capability. In addition, innovations and practices of innovation to a great extent depend on knowledge, expertise and engagement of employees. So knowledge is a valuable resource for organizations and measures to share knowledge are important. Therefore, organizations have to rely on employees as the most important organizational asset and encourage them to understand, comprehend and provide knowledge and new ideas, and practically use those ideas for the purposes of organization. So knowledge is a valuable resource for organizations and measures to share knowledge are important. In addition, most of the actions of employees in the workplace are formed and strengthened on the basis of their values and religious beliefs.

On the one hand, Islamic work ethic is based on the Quran, the sayings and deeds of Prophet Muhammad (pbuh) and Quran has shown the subject of knowledge in work, behavior and evolution of human in different ways and has supported the knowledge sharing in Islamic work ethic. Therefore, Islamic work ethic is considered as a critical action. Therefore, Islamic work ethic is considered as a critical action. This research has tested quantitative relationships between knowledge sharing capability and innovation capability with the mediating role of Islamic work ethic. This study is applied in terms of purpose and correlational descriptive survey in terms of method. Face validity of the questionnaire was measured by content validity and face validity of the research tool and its reliability was confirmed by Cronbach's alpha coefficient. In order to analyze the data, SPSS statistical software was used and to test the research hypothesis, descriptive statistics and regression tests were used. The results of the study show that knowledge sharing capability with mediating role of Islamic work ethic has an impact on innovation capability.
\end{abstract}

Keywords: knowledge sharing capability, Islamic work ethic, innovation capability 


\section{Introduction}

Innovation capability is an important strategy which organizations use as a means to achieve competitive advantage and increased survival in the global market (Turani, 1385).Innovation capability is the organization's ability to attract and use external information for transferring new knowledge (Huang, 2009). Many organizations in the competitive environment are faced with many problems and these problems are due to rapid changes in the environment, especially technological changes. In this regard, managers and employees should use the power of creativity and innovation in order to adapt and keep pace with the rapid changes, management practices and so on (Damanpour, 1991). However, the innovation theory will facilitate the integration of knowledge development and application (Montes et al., 2004). But the innovation process is quite complex and requires effective and efficient management in many different activities (Noori, 1384). On the other hand, innovations have a great tendency to employee's knowledge, expertise and engagement as a key input in the value creation process (Subramaniam, 2005). in the literature related to innovation, knowledge is considered as one of the most important components of the innovation creation process and the importance of knowledge management and its relationship to innovation is widely acknowledged (Hall and Mairesse, 2006).The main goal of knowledge management is to facilitate the creation, sharing and use of high quality knowledge to create an organization that acts intelligently. In an organization that applies the best available knowledge, knowledge management facilitates the knowledge relations and exchanges required in innovation processes. So knowledge management capacity plats a key role in supporting and nourishing innovation and without knowledge sharing, management of organizational knowledge cannot be done effectively and the organization will gradually lose their competitive advantage (Wiig, 1993). At leading organizations, knowledge management helps to build a culture of knowledge sharing among employees and by converting intellectual properties into organized human capitals, creates value for the organization. So knowledge management is one of the tools that can assist organizations in achieving their goals(Danpoort and Prosatt, 2009). Today, the most important feature in competitive world is change and organizations are forced to rely on employees as the most important organizational asset and encourage them to understand, comprehend and provide knowledge and new ideas, and practically use those ideas for the purposes of organization (Pauleen and Mosen, 2002). Meanwhile, employees are at the heart of knowledge creation process in the organization and they are the ones that create and share knowledge (Lee and Choi, 2003). On the one hand, work ethic as one of the topics covered in today's organizations is affected by factors inside and outside of the organization and identifying and controlling these factors can improve morality of employees and consequently contribute to employee productivity. Therefore, principles and attitudes about work known as work ethic in addition to have a diverse range are considered essential for person's decision to share knowledge in the workplace (Ali and Al-Owaihan, 2008). The intrinsic value of hard work that stems from Western traditions in Protestant work ethic ideology (PWE) is respected similarly in Islamic civilization and is mentioned in the Quran, the sayings and deeds of Prophet Muhammad (pbuh). Therefore knowledge sharing is realistic and can be cultivated; because it is rooted in large faiths, cultures and ideologies. Moral teachings of most religions are largely compatible and Islam recommends some of the moral values that highlight personal and social way of life (Rezk, 2008).Islamic work ethic (IWE) which is rooted in the teachings of the Quran and the Prophet of Islam (pbuh) are based on avoiding laziness, trying for well-being and prosperity of oneself and the society, legitimate and godly work, authenticity of the work that is done, avoiding fraud, negligence and tendency to altruism and philanthropy while working (Ali and Al-Kazemi, 2007).Therefore, Islamic work ethic is based on the Quran, the sayings and deeds of Prophet Muhammad (pbuh) (Ali and Al-Owaihan, 2008). But because most governmental bodies are hierarchical, systematic and less innovative organizations, sharing of knowledge becomes more difficult and employees often do not like to share their knowledge in these organizations (Cannter et al., 2011). So it seems that government agencies won't have good grounds for the emergence of innovation and creativity due to structural problems, inadequate regulation and lack of necessary responsivenss (KhoddadiHosseini, 1378). Therefore, enterprises and government agencies such as Electricity Distribution Company of Gilan province in order to create constructive ideas to enhance and improve knowledge sharing are often faced with issues such as inconsistencies or issues related to HR department. This can have a great effect on employees' innovation capability. Therefore, because of the low innovation capability, researcher had to root it out and investigate how we can help 
employees to solve this problem by improving and strengthening knowledge sharing capability and also by the mediating role of Islamic work ethic. The basic issue in this research is that what is the place of knowledge sharing capability between employees of Electricity Distribution Company of Guilan Province and how is its relationship with innovation capability of employees with moderating role of Islamic work ethic? So overall, according to the above, is significant relationship between knowledge sharing capability and innovation capability with Islamic work ethic?

\section{Theoretical literature study}

The concept of innovation and innovation capability- Innovation is important for organizations that want to exist and continue their life and organizations lacking initiative and creativity in the developed world of today actually have nothing to say. Therefore, in the present day organizations need to make an effort manage innovation and take advantage of the practical and technical achievements and pave a way to innovate and provide appropriate initiatives within their organizations (DamanPour, 1991). So today many organizations have recognized innovation as an integral aspect of providing optimal service and knowledge is seen as an incentive to achieve continuous innovation. Despite a long history of innovation in human life, organization recently by the dramatic pace of technological change, global competition and environmental uncertainty have discovered that a key and continuous source of competitive advantage and survival is innovation. This competitive advantage appears in the form of new ideas, products and services that come directly from creative thinking (Mcfadzean et al., 2005). For the definition, innovation is introduced as an idea, product or process that is new to the organization, and refers to the tendency of organizations to develop new elements or new combinations of existing elements of products, technologies, procedures or executive practices (Chen et al., 2010). By innovation we mean creativity that is expressed and has come into effect. In other words, innovation means finding creative ideas, offering new products, processes and services to market, using mental abilities to create a new idea or concept for the market, and using mental abilities to create a new thought or concept(Ahmadi and Nasiri Vahed, 1388). Rhee et al (2010) have expressed innovation as a success factor for competitive advantage. From an organizational perspective, innovation can be defined as successful use of creative facts in an organization. In this theory, creativity is a starting point for innovation by individuals and teams. Innovation is like general understanding of a new thing or method. Innovation is a result of knowledge about products, processes and services. Innovation is the introduction and application of new ideas and knowledge. Innovation involves the combination or conclusion of basic knowledge related to new products, processes or services (Rhee et al., 2010). Innovation capability is the potential of organizations to acquire new products and services, processes and ideas and increase effective economic process. In other words, innovation capability is potentially effective in providing and creating innovation (Terziovski, 2007). In other words, innovation capability is the ability of organization to attract and use external information in order to transfer new knowledge (Cohenan and Levinthhal, 1990).

The importance and necessity of innovation - Today, innovation is increasingly considered as one of the main factors of long-term success of the organization in the competitive environment. The reason for this is that organizations with the capacity to innovate can respond to environmental challenges faster and better than non-innovative organizations (Jimenez- Jimenez, 2008). So innovation is the very important for the organizations; because it can provide a sustainable competitive advantage for them (Weerawerdena and Julion, 2006). In this regard today, innovation is very important for organizations that want to exist and continue their life. Organizations lacking initiative and creativity in the developed world of today actually have nothing to say. Therefore, in the present day organizations need to make an effort manage innovation and take advantage of the practical and technical achievements and pave a way to innovate and provide appropriate initiatives within their organizations (DamanPour, 1991).

The concept of knowledge sharing- Knowledge is a concept emerged from the thought that without it can be considered as information and data. Only through this concept information come to life and become knowledge (Riches, 2004). Knowledge is a valuable resource for the organization. The manager must be able to flourish the knowledge lying in its human resources by applying efficient 
management, because only in this way he/she can deal with uncertain environment and also reach organizational goals. Knowledge is a fluid mix of experiences, values, contextual information, and expert knowledge that provide a coherent and integrated framework for the assessment and acquisition of business and new information. This knowledge comes from the minds of people and is used by them. This knowledge exists not only within the organization's documentation and databases, but also in of all the activities, processes and practices of organization. Organizational knowledge is everything that people in the organization know about processes, products, services, customers, markets and competitors (Alvani et al., 1386). Knowledge management includes the study of strategy, process and technology to acquire, select, organize, decide and apply expertise and critical information for businesses in order to improve the quality and efficiency of the organization. In general, knowledge management can be defined as a set of processes that govern the creation, dissemination and utilization of knowledge. This definition requires the creation of organizational structures, support, facilitating the relations between the members, using information technology tools and distribution of knowledge (Gupta and Sharma, 2004).Wiig (1993) also believes that Knowledge management means establishing processes necessary to identify and capture data, information and knowledge from internal and external environments needed by the organization and transform them into decisions and actions of organizations and individuals (Wiig, 1993). Gupta and Macdaniel (2002) believe that knowledge management is a process by which organizations acquire skills in the field of learning, coding, sharing, distributing and transmitting knowledge. Knowledge management consists of two aspects of knowledge management and ability to create new knowledge. The purpose of first aspect is the provision of information needed by the applicant at the right time. The second aspect includes the activities of acquisition, integration, distribution, and application of knowledge to improve the organization's operations (Gupta and Macdaniel, 2002). On one hand, the sharing of knowledge is one of the key areas in knowledge management. Among the issues that are in line with the implementation of knowledge management, the issue of knowledge sharing within the organization and between different organizations is important. Knowledge sharing can be defined as the systematic activities of transferring and exchanging knowledge and experience between the members of a group or organization. Effective sharing of knowledge between members of the organization will reduce costs, improve service quality, improve corporate communications, shorten the work processes, disseminate best practices and improve organizational performance. Knowledge sharing by employees is formed when individuals voluntarily and willingly share their knowledge with others and collect the knowledge they need from others eagerly and thus, create a cycle of knowledge sharing within the organization (Yousefi et al., 1390). So knowledge sharing is a process through which employees can exchange and create new knowledge. Therefore, the importance of knowledge sharing in order to improve innovation capability is significant (Saifuddin et al., 1385).

The importance of knowledge sharing - One of the priorities stated by the researchers of knowledge management is to motivate people to share their knowledge (Kegans, 2009). Knowledge sharing has been proposed as a critical element for organizations to develop integrated services, resource sharing and efforts to promote organizational learning and creativity and innovation (Khatemiyan Far, 1386). The role of knowledge sharing in knowledge management is so important that some authors argue that knowledge management exists in order to support knowledge sharing. Although some believe that knowledge is power, but it seems that knowledge has no power in itself but something that gives power to the people is part of the knowledge that they have shared with others (McDermott, 2007).

Islamic work ethic- Work ethic is a rational thinking process which aims at the showing this fact that when organization must preserve and promote what values. It is a set of accepted moral actions and reactions established by the professional organizations and associations to provide the most desirable social relationships for its members when performing professional duties (Azad and arshadi, 1388). Work ethic is the most important cultural factor in economic development (KhaniJazani, 1387). In other words, work ethic is a cultural norm that gives positive spiritual value to doing good work in the community and believes that the work itself has an intrinsic value (Rahimnia et al., 1389). Work ethic is a manifestation of personal values that encourage people to share knowledge and work not only because of personal interests, but social and organizational benefits. And these values make it possible to internalize knowledge sharing responsibilities between individuals in government 
organizations (Porter, 2010). On the one hand, Islamic work ethic which is rooted in the teachings of the Quran and the Prophet of Islam (pbuh) are based on avoiding laziness, trying for well-being and prosperity of oneself and the society, legitimate and godly work, authenticity of the work that is done, avoiding fraud, negligence and tendency to altruism and philanthropy while working; And these teachings that find their ways from the society into the organizations are in contrast with behaviors such as theft, laziness, personal use of organization's properties, abusing fellow colleagues, ridicule, or pranks and jokes (Ali and Al-Kazemi, 2007). Therefore, Islamic work ethic is based on the Quran, the sayings and deeds of Prophet Muhammad (pbuh) and Quran has shown the subject of knowledge in work, behavior and evolution of human in different ways and has supported the knowledge sharing in Islamic work ethic (Khalil and Abusaad, 2009).

The conceptual model of research- Knowledge is known as the most important factor of competition and along with the knowledge and innovation, it is considered as the most important factor for survival of the organization. Therefore, knowledge creation, knowledge transfer and knowledge application that are among the main activities of knowledge management can improve organization's intellectual capital and the final output of intellectual capital in organization is innovation (Ramezani and Hasanavi, 1390). The role of knowledge sharing in knowledge management is so important that some authors argue that knowledge management exists in order to support knowledge sharing (McDermott, 2007). Knowledge sharing is the most important fundamental part of the knowledge management process (Bock and Kim, 2002.) and knowledge have been proposed as a part of the innovation process and the importance of knowledge management and its relationship with innovation is widely acknowledged (Hall and Mairesse, 2006). Work ethic is a manifestation of personal values that encourage people to share knowledge and work not only because of personal interests, but social and organizational benefits and these values make it possible to internalize knowledge sharing responsibilities between individuals in government organizations (Porter, 2010). On the one hand, Islamic work ethic is rooted in the teachings of the Quran and the Prophet of Islam (pbuh) (Ali and Al-Kazemi, 2007). Quran has shown the subject of knowledge in work, behavior and evolution of human in different ways and has supported the knowledge sharing in Islamic work ethic (Khalil and Abusaad, 2009). The conceptual model is an analytical tool by which the study variables and the relationship between them is determined. Conceptual model based on the relationship between the knowledge sharing capability and innovation capability with the mediating role of Islamic work ethic is shown in Figure 1, which has used Kumar and Che Rose research method as the research conceptual model (Narech Kumar and Raduan Che Rose, 2010). In this model, knowledge sharing capability is measured as an independent variable, Islamic work ethic as a moderating variable and innovation capability as a dependent variable.

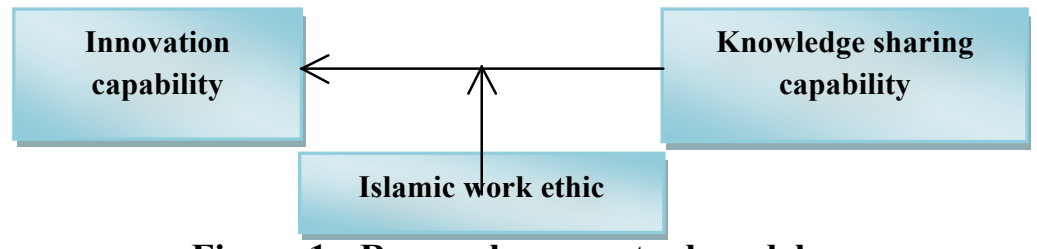

Figure 1 - Research conceptual model

A study was conducted by Kazemi Esfeh (1393) as his thesis titled "The impact of knowledge sharing enablers on innovation capability with the moderating role of Islamic work ethic among employees and managers of Isfahan Gas Company. The results of this study showed that knowledge sharing enablers affected innovation capability; also knowledge sharing capability affected innovation capability and finally the moderating effect of Islamic work ethic on the relationship between knowledge sharing capability and innovation capability was not confirmed. Also a study was conducted by Kumar and Che Rose (2010) titled "The impact of knowledge sharing on o innovation capability with the moderating role of Islamic work ethic among administrative and diplomatic service officers in public sector organizations of Malaysia. Results of this study showed that intrinsic motivation for sharing knowledge in organizations of the public sector is very important. The relationship between employees' knowledge sharing and innovation capabilities was subject to Islamic work ethic and has been approved. Also enablers of enjoying helping others, self-efficacy of 
knowledge, general confidence and knowledge of shared norms affected knowledge sharing capability and enablers of mutual relations among employees, self-knowledge and employees' perception of organizational rewards didn't affect knowledge sharing capability.

According to the conceptual model of research and mentioned materials, the research hypotheses are as follows.

1. The knowledge sharing capability has an effect on innovation capability.

2. The knowledge sharing capability with the mediating role of Islamic work ethic has an effect on innovation capability.

\section{Research method}

In terms of research categories according to purpose, this study can be considered an applied research and in terms of method, it is correlational descriptive, since it describes and characterizes the variables of a situation and also collects data and factual information, identify and address issues and compares, evaluates and assesses the study variables. The population of this study consisted of employees of Electricity Distribution Company of Guilan which has 600 staff. Given the limited size of the study population, Cochran formula was used to determine the sample size and the number of members was 235 and in order to enhance the credibility of the study, 250 questionnaires were distributed among these employees. The sampling method used in this study is available non-probability sampling. In order to collect data and information, field method and questionnaire are used and the research tools are based on standard questionnaires. Standard questionnaire of Kim and Lee (2006) was used in the section of knowledge sharing capability; standard questionnaire of Ali (1992) was used in Islamic work ethics section and standard questionnaire of Lee and Choi (2003) was used in the section of innovation capability. In this study, face validity of the questionnaire was measured by content validity and face validity of the research according to the experts' approval in the field of management and for determining the reliability of this questionnaire with an emphasis on internal consistency of the measuring tool that measures different features, Cronbach's alpha coefficient method was used. By using SPSS statistical software, Cronbach's alpha for the variables of knowledge sharing, Islamic work ethic, innovate capability and the entire questionnaire were calculated and approved respectively as $0 / 62,0 / 75,0 / 86$ and $0 / 92$. In order to analyze the data, SPSS statistical software was used and to test the research hypothesis, descriptive statistics and regression tests were used.

\section{Analyzing the data}

Descriptive statistics of the research variables - Descriptive data of the research variables such as knowledge sharing capability, Islamic work ethic and innovation capability of the respondents in Table 1 show that the average for the variable of knowledge sharing capability was 3/93 and its standard deviation was $0 / 81$, the average obtained for Islamic work ethic variable was 3/94 and its standard deviation was $0 / 76$ and also the average obtained for innovation capability variable was 4/02 and its standard deviation was $0 / 76$ and given the total average $(3 / 5)$, it shows that the variables of knowledge sharing, Islamic work ethic and innovation capability of the respondents are at a favorable level.

Table 1 - descriptive statistics of research variables

\begin{tabular}{|c|c|c|c|c|c}
\hline Research variables & Number & $\begin{array}{c}\text { Minimum } \\
\text { amount }\end{array}$ & $\begin{array}{c}\text { Maximu } \\
\text { m amount }\end{array}$ & Average & $\begin{array}{c}\text { Standard } \\
\text { deviation }\end{array}$ \\
\hline Knowledge sharing & 235 & 1 & 5 & $3 / 9262$ & $0 / 8126$ \\
\hline Islamic work ethic & 235 & 1 & 5 & $3 / 9389$ & $0 / 7676$ \\
\hline Innovation capability & 235 & 1 & 5 & $4 / 0230$ & $0 / 7589$ \\
\hline
\end{tabular}

Check the normality of variables - To test the research hypothesis, normality of the data and information must be examined at first. In fact, when normality or abnormality of data is realized, then 
appropriate tests can be used. In this study the Kolmogorov-Smirnov test was used to check the normality of the study variables and the results are presented in Table 2.

Table 2 - Checking the normality of study variables

\begin{tabular}{|c|c|c|c}
\hline Research variables & $\begin{array}{c}\text { Kolmogor } \\
\text { ov- } \\
\text { Smirnov }\end{array}$ & $\begin{array}{c}\text { Significance } \\
\text { level }\end{array}$ & Condition \\
\hline Knowledge sharing & $2 / 037$ & $0 / 088$ & Normal \\
\hline Islamic work ethic & $1 / 387$ & $0 / 143$ & Normal \\
\hline Innovation capability & $1 / 547$ & $0 / 217$ & Normal \\
\hline
\end{tabular}

Measurement of knowledge sharing capability- In the framework of this research, the knowledge sharing capability is an independent variable and in order to measure the knowledge sharing capability among staff of Electricity Distribution Company of Guilan, three questions in Likert scale with options "absolutely agree" and " absolutely disagree" from the standard questionnaire of Kim and Lee (2006) were used.

Measurement of Islamic work ethic- In the framework of this research, Islamic work ethic is an mediating variable and in order to measure the knowledge sharing capability among staff of Electricity Distribution Company of Gilan,13 questions in Likert scale with options "absolutely agree" and " absolutely disagree" from the standard questionnaire of Ali (1992) were used.

Measurement of innovation capability- In the framework of this research, innovation capability is an dependent variable and in order to measure the knowledge sharing capability among staff of Electricity Distribution Company of Gilan,5 questions in Likert scale with options "absolutely agree" and " absolutely disagree" from the standard questionnaire of Lee and Choi (2003) were used.

Regression analysis- To assess the mediating role of Islamic work ethic variable in the relationship between knowledge sharing and innovation capabilities, regression analysis and Statistical Package for Statistical Package for Social Science (SPSS statistical software) was used. The following conditions must be met for using regression analysis.

1. Measuring scale of research variables should be at least ranking and five-point Likert scale is used here.

2. The distribution of the dependent variable values (knowledge sharing and innovation capabilities) should be normal and according to the results of Kolmogorov-Smirnov test (Table 2), the distribution of all the variables was normal.

3. The linear relationship between the variables and analysis of variance (ANOVA) and calculating F should be approved and the significance of regression equation was calculated using $\mathrm{F}$ test in both groups and is shown in Table 3.

4. Independence of observations should be determined by Durbin - Watson test. If the value of this test is between $1 / 4$ and 2/4, then observations are independent from each other. The value of this test in the table related to regression coefficients is given in Table 3 which is in the proper range.

Multiple correlation coefficients (R) in Table 3 show the intensity of the relationship between independent variables and the dependent variable. This value is always between 0 and +1 . Coefficient of determination (R2) shows that only a few percent of the changes in dependent variable of market is the result of independent variables. But to show the importance of independent variables (Islamic work ethic) in predicting the dependent variable (knowledge sharing and innovation capabilities) and generally predicting the regression equation, standard values (Beta) should be noted. Therefore the standardized effect coefficient $(\beta)$ help us determine the relative contribution of each independent variable in explaining the changes of the dependent variable.

Table 3 - Results of regression test 


\begin{tabular}{|c|c|c|c|c|c|c|c|c|c|}
\hline \multirow{2}{*}{ 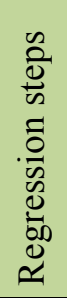 } & \multirow{2}{*}{$\begin{array}{l}\text { Input } \\
\text { variabl } \\
\text { e }\end{array}$} & \multicolumn{2}{|c|}{$\begin{array}{c}\text { Not } \\
\text { standardized } \\
\text { coefficients }\end{array}$} & \multirow{2}{*}{$\begin{array}{c}\begin{array}{c}\text { Standardiz } \\
\text { ed } \\
\text { coefficients }\end{array} \\
\begin{array}{c}\text { Beta } \\
\text { coefficient } \\
(\beta)\end{array}\end{array}$} & \multirow{2}{*}{$\begin{array}{l}\text { Statistic } \\
\text { S } \\
\mathrm{T}\end{array}$} & \multirow{2}{*}{$\begin{array}{l}\text { Significan } \\
\text { ce level. }\end{array}$} & \multirow{2}{*}{$\begin{array}{l}\text { Analysis } \\
\text { of } \\
\text { Variance }\end{array}$} & \multirow{2}{*}{$\begin{array}{c}\text { Durbi } \\
\mathrm{n}- \\
\text { Watso } \\
\mathrm{n} \\
\text { statisti } \\
\mathrm{c}\end{array}$} & \multirow{2}{*}{$\begin{array}{c}\text { The } \\
\text { explaine } \\
d \\
\text { variance }\end{array}$} \\
\hline & & B & $\begin{array}{l}\text { Standar } \\
d \text { error }\end{array}$ & & & & & & \\
\hline 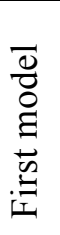 & $\begin{array}{c}\text { Consta } \\
\text { nt } \\
\text { Islamic } \\
\text { work } \\
\text { ethis }\end{array}$ & $\begin{array}{c}1 / 23 \\
0 \\
3 / 96 \\
9\end{array}$ & $1 / 623$ & $0 / 537$ & $10 / 758$ & $0 / 000$ & $\begin{array}{c}F=94 / 35 \\
6\end{array}$ & $1 / 812$ & $\begin{array}{c}\mathrm{R}^{2}=0 / 28 \\
8 \\
\text { Adjuste } \\
\mathrm{d} \mathrm{R}^{2} \\
=0 / 285\end{array}$ \\
\hline
\end{tabular}

According to regression test results in Table 3 and the results of analysis of variance, linear relationship between the independent variable (Islamic work ethic) and the dependent variable (knowledge sharing and innovation capabilities) is confirmed. Durbin - Watson statistic was also in the range between $1 / 5$ and $2 / 5$ and it shows that the observations were independent of each other Also, due to the significant level of less than $0 / 05$, regression between Islamic work ethic variable and knowledge sharing and innovation capabilities variables in the employees is approved $(\beta=0 / 537)$. So the hypothesis of Islamic work ethic's moderating role in the relationship between knowledge sharing capability and innovation capability is approved.

\section{CONCLUSION}

Mediating variable of Islamic work ethic in the relationship between knowledge sharing and innovation capabilities at very high levels was measured among staff. Knowledge sharing is realistic and can be fostered and it is rooted in large religions, cultures and ideologies. In many verses and hadiths of Quran the importance of knowledge and the pursuit of knowledge, training and knowledge sharing is emphasized and encouraged. Work ethic is a manifestation of personal values that encourage people to share knowledge and work not only because of personal interests, but social and organizational benefits. Islamic work ethic is applicable in every aspect of people's lives, including organizational management. Therefore the working environment and religious beliefs and Islamic values play every valuable role in the development of innovation among employees Considering the high potential of human resources in Electricity Distribution Company of Guilan province in terms of education level (90\% having bachelor and master degrees), to boost innovation capability among employees with a moderating role of Islamic work ethic the following proposals are presented:

1. Strengthening excellent work culture among employees using the correct teachings, Islamic beliefs and values such as equality, accountability, consultation, trust, kindness, respect for the promises (pledge), honesty, fairness, hard work, humility, perseverance, cooperation, discipline, agreement and understanding.

2. Using Islamic factors and creating the right atmosphere for productive work among employees using Islamic doctrines, beliefs and values such as equality, accountability, consultation, trust, kindness, respect for the promise (pledge), honesty, fairness, hard work, humility, perseverance, cooperation, discipline, agreement and understanding.

The most important limitation of the study that is one of the certain features of social science researches is the influence of variables that controlling them is beyond the reach of researcher and their possible influence on the results is not far-fetched One is that data of this study were collected in cross-sectional method, so the results may be limited to a period of time. The other is that this study is limited to Electricity Distribution Company of Guilan province, so generalizing the results to other companies and government agencies do not seem appropriate. Therefore it is recommended that in order to collect detailed information for a full analysis of the data, the longitudinal approach and other tools should be used for data collection. Also a similar research should be carried out in other governmental organizations, such as water and sewage and gas and the results obtained from this study should be compared with the findings. Since the Islamic work ethic in this study is focused on the human aspects, in order to measure innovation among employees more functionality, it is 
recommended that the internal structures (attitude, strategies, goals, values, culture and philosophy of the individual) and external structures (shareholders, policies) of the organization also be used.

\section{REFERENCES}

1. Ali, A.J, and Al-Owaihan, a. (2008). Islamic work Ethic: a critical review, Cross Cultural Management: An International Journal, 15.1.5-19.

2. Ali, A.J., A, Al-kazemi, A. (2007). Islamic work ethic in Kuwait, Cross Culture Management: An International Journal, 14.2.93-104.

3. Ahmadi, P., Nasirivahed, N.(1388). Designing and explaining the factors affecting organizational innovation in Iran Transfo Group Factories, Management Research, 2.4.155-178

4. Alvani, S.M, Nategh, T, Farachi,M.M.(1386). The role of social capital in knowledge management development, Iran Journal of Management Sciences, 5.35-70

5. Azad, N., Arshadi, E.(1388). Investigating the influence of organizational culture 0n perceived support of innovation ( Case study of specialized holding company of Government Commerce), Journal of Management trade, 26-38

6. Bock, G.W., and Kim, Y.G.(2002). Breaking the myths of rewards: an exploratory study of attitudes about knowledge sharing ,Information Resources Management Journal, 15.2.14-21

7. Cantner, U., Kristin, J and Tobias, S. (2011). The effects of knowledge management on innovative success-an empirical analysis of germanforms , Research policy, 40 .1453-1462

8. Chen chung-jen, Hung jing-wen, Hsiao yung-chng (2010). Knowledge management and innovativeness: the role of organizational innovation: A meta-analysis of effects of deter mints and moderators, Academy of Management Journal,34.3.555-590

9. Cohen, W.M., Levinthhal, D, A., (1990). Absorvative capacity: a new perspective on learning and innovation, Administrative Science Quarterly, 35.128-152

10. Damanpour, F. (1991). Organizational innovation: A Meta analysis of effects of determanants and moderators .Academy of Management Journal, 34.585

11. Danpoort, E\& prosatt, B.(2009). The role of knowledge management in universities gools, (http://www.knowledge management sharing.com)

12. Gupta, A., Macdaniel, J. (2002). Creating Competitive Advantage by effectively Management knowledge: A Frame work for knowledge Management, Journal of Knowledge Management practice.

13. Gupta, J.N.D, Sharma, S.K. (2004). Creating knowledge Base organization, Idea Group Publishing. 1-15

14. Hall, R.and Mairesse, J .(2006). Empirical studies of innovation in the knowledge driven economy, Economics of Innovation and new Technology 15.4.296-321

15. Huang C. (2009). Knowledge sharing and innovation and group cohesiveness on performance: an empirical study of technology R\&D teams in taiwan, Journal of Information Science Research ,20.786-797

16. Jimenez-jimenez, Daniuel . (2008). Fostering innovation organizational learning and performance, Jounal of Business Research, 64. 408-417

17. Khalil, M., Abu-Saad, I.(2009). Islamic work ethic among arab college students in inisrael, Cross Culture Management an International Journal of Management Information, 23.3.333-347

18. Kegans, L. (2009). Occupational work ethic differences: implications for organization for organizational diversity inititativees in health care organizations, performance Improvement Quarterly, 22.3.83-94

19. Khatemiyan Far, p.(1386). Reviewing the situation and ways to share knowledge of Astan Quds Razavi Library, MS thesis for Library and Information Science, Mashad, Ferdowsi University of Mashhad, Faculty of Education and Psychology

20. Khanjanani, J.(1378). The work ethic and entrepreneurial work ethic, Journal of Ethics in Science and Technology, 3.4.91-96

21. Khoddad Hosseini, H.(1378). Innovation in organizations: Concept, Types and processes, Journal of Economics and Management, 42.85-114

22. Lee,heeseok.\&choi byounggu.(2003). knowledge management enablers, processes and organizational performance :An integrative view and empirical examination journal of management information system,summer 2003,105.2.208-222 
23. McDermott R, O'Dellc. (2007). Overcoming culture barris to sharing knowledge, Journal of Knowledge Management, 5. 1. 76-83

24. Mcfadzean, E.: oloughlin,A.\&shaw,E.(2005). Corporate entreprenceurship and innovation part1:the missing link,European journal of innovation management,8.3.350-372

25. Montes, F, J., Moreno, A.R, Fernandez, L.M, (2004). Assessing the organizational climate and contractual relationship for perceptions of support for innovation , International Journal Manpower, 25.2.167-180

26. Nouri, S.(1384). Knowledge management tool for product innovation, Individual Management, 3.11.52-80

27. Pauleen, D \& Moson, D.Newzealad.(2002). Knowledge management: barriers and drivers of knowledge management uptake, Journal of Knowledge Management, 8.5.23-54

28. Porter, G, .(2010). Work ethic and ethical work: distortions in the American dream, Journal of Business ethics, 96.533-550

29. Rahimnia, F., Gharabaghi, N., Behpour, E., Mallaie, Z.(1389). A conceptual model to investigate the relationship between work ethics and spirituality, entrepreneurship and organizational performance, The First International Conference of Management, Innovation and Entrepreneurship, Shiraz

30. Ramezani, M., Hasanavy, R.(1390). Knowledge productivity in knowledge- based organizations, Publications Atinegar

31. Rezk, R.R(2008). Back to basics an Islamic perspective on business and work ethics, Social Responsibility Journal, 4.2.246-257

32. Rhee jaehoon, park b aekyung, Lee C Dohgung .(2010). Drivers of innovativeness and for performance innovative SMES in South Korea: Mediation of learing orientation, techno Innovation 30.65-75

33. Riches, Paul. (2004).organizational coherence and knowledge management, KM Rreview Brifing, 7.4

34. Saifuddin, A.A., Salemi, M.H., Seeid Esfahani, M.M.(1385). Comparing knowledge sharing and transfer of knowledge at different levels of innovation systems, Journal of Humanities lecturer, 4.77-110

35. Subramaniam, M., youdt, M.A (2005). The influence of intellectual capital on the types of innovation capabilities, Acad Management Journal. 48.3.450-463

36. Terziovski, Mile. (2007). Bullding innovation capability in organization: An International crosscase perspective, University of Mellburn Australia

37. Torani, h.(1385). Investigating the implications of management theory and styles in innovation updating, Quarterly Educational Journal, 85-114

38. Weerawardena, J.O., O cass, A., \& Julian, C.(2006). Does industry matter? Examining the role of industry structure and organizational learning in innovation and brand performance, Journal of Business Research.

39. Wiig k.M.(1993). Knowledge management foundations thinking about thining how people \&organization creat.represent \&use knowledge: schema press.jan 1.1993.471

40. Yousefi, E., Sadegh Feizi, J., Soleimani, M.(1390). Evaluating the impact of knowledge management on innovation (case study among employees and managers of IT companies based in Urmia University of Science and Technology Park), Journal of Initiative and Creativity in Science, $1.3 .29-51$ 